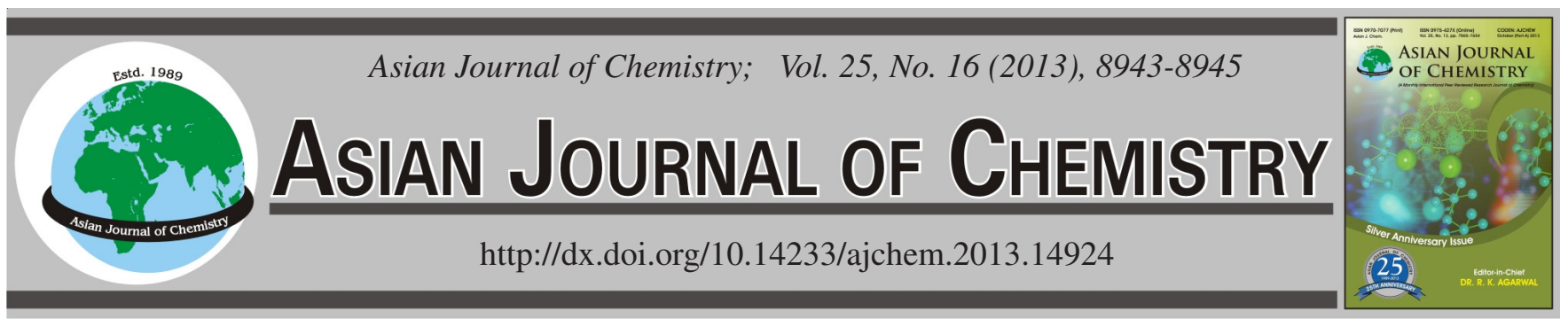

\title{
Behaviour and Quantification Studies of Venlafaxine Using Differential Pulse Stripping Voltammetric in Capsules
}

\author{
Ping Qiu ${ }^{1, *}$, Congsen Liu ${ }^{1}$, DAiqin Lin ${ }^{2}$ and Guang Zeng ${ }^{1}$
}

${ }^{1}$ Department of Chemistry, Nanchang University, Nanchang 330031, P.R. China

${ }^{2}$ Jiangxi Provincial Product Quality Supervision Testing College, Nanchang, P.R. China

*Corresponding author: Tel: +86 791 83969514; E-mail: pingqiu@ @cu.edu.cn

(Received: 5 December 2012;

Accepted: 9 September 2013)

AJC-14086

\begin{abstract}
A simple and rapid voltammetric method has been developed for the quantitative determination of venlafaxine in pharmaceutical capsules. Studies with differential pulse stripping voltammetry (DPSV) were carried out using a hanging mercury drop electrode (HMDE) in Britton-Robison buffer. A well-defined oxidation peak of venlafaxine was obtained at $-432 \mathrm{mV} v s$. Ag/AgCl. The optimum working conditions for the determination of the compound were established. The detection and quantification limits were found to be 0.0993 and $0.1 \mu \mathrm{g} / \mathrm{mL}$, respectively. An analysis of real samples containing venlafaxine showed no interferences with common additives and excipients. The method proposed does not require any pretreatment of the pharmaceutical capsules. A HPLC determination of venlafaxine in capsule samples diluted was also performed for comparison.

Key Words: Venlafaxine, Differential pulse stripping voltammetry, Determination.
\end{abstract}

\section{INTRODUCTION}

Venlafaxine (1-[2-(dimethylamino)-1-(4-methoxyphenyl) ethyl]cyclohexanol) is a third generation antidepressant drug ${ }^{1}$ which selectively inhibits re-uptake of norepinephrine and serotonin, with weak inhibition of dopamine re-uptake ${ }^{2,3}$.

Since venlafaxine is given in low doses, a sensitive procedure is desired for its determination and testing content uniformity of its dosage form. High-performance liquid chromatography (HPLC) has been used to quantify venlafaxine in biological fluides ${ }^{4}$ and also applied to bioequivalence studies ${ }^{5}$. The determination of venlafaxine in human plasma has been carried out by using HPLC-spectrofluorimetry ${ }^{6}$, HPLC-MS ${ }^{7,8}$. Generally for drugs determination distribution techniques i.e. chromatography are used; rarely spectroscopic and electroanalytical methods. Electroanalytical methods could be used as a comparative methods for others methods in inter-laboratories researches or in certified reference materials (e.g., urine with different drugs) preparation or as a detection methods in HPLC. Lima has described the square wave voltammetric behaviour of venlafaxine'.

Differential pulse stripping voltammetry has been shown to be an efficient electroanalytical technique for determination of sub-nanomolar level of a wide range of drugs. It ususlly involves a simple accumulation step and most of the excipients used do not interfere in the subsequent determination of the drugs ${ }^{10}$. The technique is easy to use and save of both time and costs.

Here we aimed to describe a fully validated simple, precise and selective differential pulse stipping voltammetric procedure for the trace quantificaiton of venlafaxine in pharmaceutical capsules. And, the current electroanalytical research aimed to study the voltammetric behaviour of venlafaxine and its interfacial adsorptive accumulation onto the hanging mercury drop electrode.

\section{EXPERIMENTAL}

A standard stock solution of $100 \mu \mathrm{g} / \mathrm{mL}$ venlafaxine was prepared by dissoving an accurate quantity of the authentic substance in distilled water then stored at $4{ }^{\circ} \mathrm{C}$. More dilute solution were prepared by accurate dilution with distilled water. A series of Britton-Robinson (B-R) universal buffer ( $\mathrm{pH} 1.98$ 11.89) was prepared ${ }^{11}$ and used as a supporting electrolyte. Othre chemicals used were all of analytical reagent grade and distilled water was used throughout the experiment.

A BAS-100B/W electroanalyzer (BAS) equipped with a PAR (Princeton) Model 303A static mercury drop electrode system was used for all the electrochemical measurements. Voltammetric current was measured against an $\mathrm{Ag} / \mathrm{AgCl}$ ( $3 \mathrm{~mol} / \mathrm{L} \mathrm{KCl}$ ) reference electrode and a platinum wire was used as the auxiliary electrode. HPLC-DAD system (Agilent 1100) equitpped with a G1379A vacuum degasser, a G1311A 
quaternary pump, a G1313A autosampler, injector with a 100 $\mu \mathrm{L}$ loop and a $\mathrm{G} 1315 \mathrm{~B}$ diode array detector.

Voltammetric procedure: A suitable amount of the venlafaxine standard solution, together with $2 \mathrm{~mL}$ the B-R buffer were transferred to an electrochemical cell and diluted to $10 \mathrm{~mL}$ with distilled water. The solution was purged with purified nitrogen for $6 \mathrm{~min}$. An accumulation potential of -0.1 $\mathrm{V}$ was then applied to the hanging mercury drop for an accumulation duration of $1 \mathrm{~min}$ while the solution was stirred. At the end of the accumulation duration, the stirring was stopped and a $10 \mathrm{~s}$ rest period was allowed for the solution to become quiescent. The voltammograms were then recored and examples of voltammetric curves of venlafaxine (Fig. 1) show the peak potential at $-432 \mathrm{mV}$.

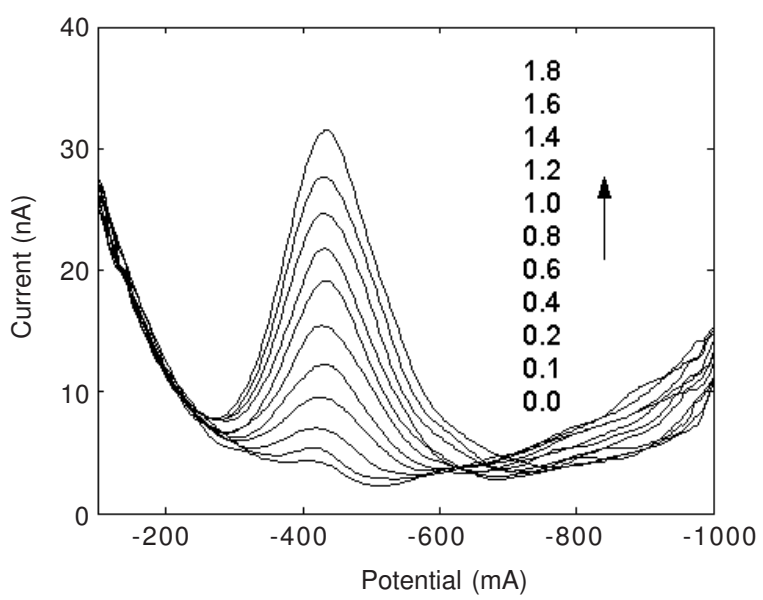

Fig. 1. Differential pulse voltammograms of venlafaxine solutions with different concentrations $(\mu \mathrm{g} / \mathrm{mL})$ at a HMDE in B-R buffer of $\mathrm{pH}$ 3.72

HPLC procedure: HPLC method for the determination of venlafaxine available in the literature ${ }^{12}$ was used to compare the analytical results obtained with the developed voltammetric procedure. Experiments were carried out using a Agilent 1100 chromatographic pump. The mobile phase was prepared by mixing $255 \mathrm{~mL}$ of acetonitrile with $745 \mathrm{~mL}$ of $0.1 \mathrm{~mol} / \mathrm{L}$ $\left(\mathrm{NH}_{4}\right) \mathrm{H}_{2} \mathrm{PO}_{4}$, which was afterwards filtered through a $0.45 \mu \mathrm{m}$ filter and degassed with a helium sparge.

\section{RESULTS AND DISCUSSION}

Cyclic voltammetry studies: Cyclic voltammograms (Fig. 2) of venlafaxine at a hanging mercury drop electrode in the B-R universal buffers of 1.89-9.38 exhibited a well-difined irreversible peak which may be attributed to oxidation of the $-\mathrm{OH}$ bond. The potentials $\left(\mathrm{E}_{\mathrm{p}}\right)$ shifted to more negative values upon rise either the $\mathrm{pH}$ of solution and scan rate $v$ (10-500 $\mathrm{mV} / \mathrm{s}$ ) which confirmed, respectively, the involvement of protons in the electrode reaction ${ }^{13}$ and the irreversible nature of the reduction process ${ }^{14}$.

The interfacial adsorptive character of venlafaxine was identified by recording the cyclic voltammograms of $2.0 \mu \mathrm{g} /$ $\mathrm{mL}$ in a B-R buffer following its accumulation onto the hanging mercury dropping electrode (HMDE). A much developed peak current intensity (curve 1) was achieved following accumulation of venlafaxine onto the hanging mercury dropping electrode

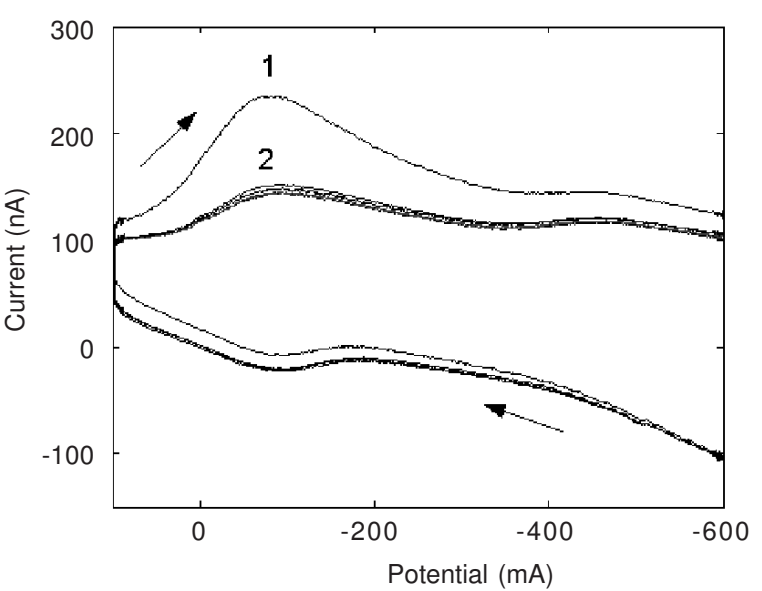

Fig. 2. Cyclic voltammograms of $2.0 \mu \mathrm{g} / \mathrm{mL}$ venlafaxine in a B-R buffer of $\mathrm{pH} 3.72$

surface at $-0.1 \mathrm{~V}$ whereas its second cycle at the same mercury drop (curve 2) exhibited a lower peak current intensity. This behaviour indicated the interfacial adsorptive character of venlafaxine onto the mercury elctrode surface.

The linear sweep voltammetry oxidation signal was studied in the range of $10-500 \mathrm{mV} / \mathrm{s}$ with different scan rate at an HMDE. It was observed that the plot (Fig. 3) of $\log \mathrm{i}_{\mathrm{p}}$ versus the $\log v$ for peak was a straight line with slope of 0.43 , as expected theoretically when there is adsorption at the electrode surface $^{15}$. This result indicates that the venlafaxine molecules are strongly adsorbed and accumulated at the mercury electrode surface. The adsorption of venlafaxine on the HMDE can, consequently, be used as an effective preconcentration step before quantitative measurements are undertaken. Owing to its better analytical characteristics, the voltammetric technique used in the stripping step was differential pulse stripping voltammetry (DPSV).

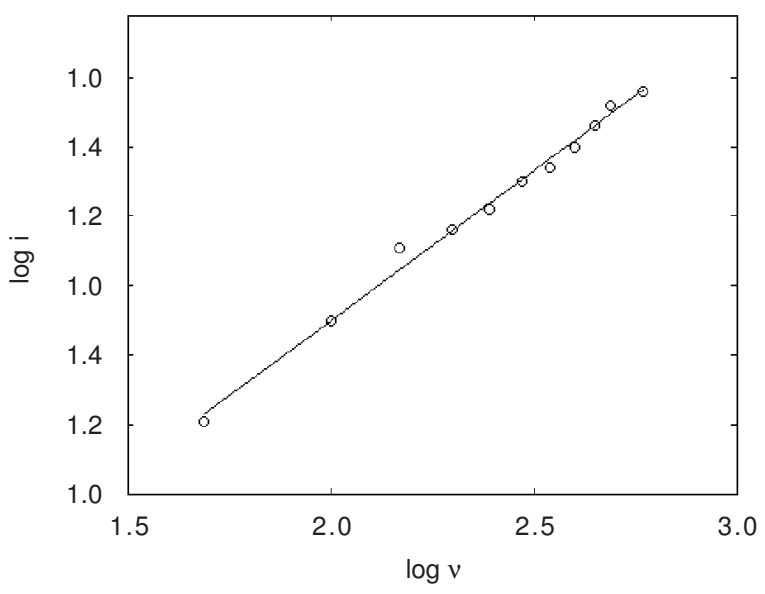

Fig. 3. Plot of $\log v$ versus $\log$ i for venlafaxine

Differential pulse stripping voltammetry studies: The observed DPSV signal was vitally $\mathrm{pH}$-dependent since intense electrochemical currents were only observed at mild acidic media. When the influence of buffer acidity on the observed analytical signal for venlafaxine was investigated over the $\mathrm{pH}$ range 1.89-9.38, it was noticed that weak analytical signals were obtained if buffer solutions with $\mathrm{pH}$ values out of the 
range 6.8-9.38. After $1 \mathrm{~min}$ accumulation time for $0.8 \mu \mathrm{g} / \mathrm{mL}$ venlafaxine solution at $-0.1 \mathrm{~V}$ preconcentration potential, the highest peak height was achieved at $\mathrm{pH} 3.72$ and beyond this optimum $\mathrm{pH}$ value the monitored adsorptive stripping response decreased gradually. Furthermore, the peak potential was found to be dependent on the $\mathrm{pH}$ of the buffer solution. A gradual shift to more positive potential was observed form -456 to $-304 \mathrm{mV}$ when varying $\mathrm{pH}$ value over the range, indicating consumption of hydrogen ions in the electrochemical oxidation process.

The effect of varying the accumulation time $\left(\mathrm{t}_{\mathrm{acc}}\right)$ from 0$90 \mathrm{~s}$ on the peak current intensity of the DPSV voltammogram for $0.8 \mu \mathrm{g} / \mathrm{mL}$ venlafaxine was also evaluated. It is found that the peak current intensity is a linear relationship with the accumulation duration up to $1 \mathrm{~min}$.

Calibration: A linear calibration curve for venlafaxine was calculated over the concentration of $0.1-1.8 \mu \mathrm{g} / \mathrm{mL}$ for the peak current measurments (Fig. 1) obtained under the experimental conditions described above. The calibration parameters (Table-1) indicate a good fit to the linear model and the computed detection limit ${ }^{16}$ was $0.0993 \mu \mathrm{g} / \mathrm{mL}$. The relative standard deviation (RSD) was $3.6 \%$, which indicate excellent reproducibility.

\begin{tabular}{lc}
\multicolumn{2}{c}{ TABLE-1 } \\
\multicolumn{2}{c}{ PARAMETERS OF THE DPSV CALIBRATION } \\
\multicolumn{1}{c}{ PLOT FOR VENLAFAXINE } \\
\hline \multicolumn{1}{c}{ Parameters } & Values \\
\hline Linear range $(\mu \mathrm{g} / \mathrm{mL})$ & $0.1-1.8$ \\
Calibration equations $(\mathrm{i}=\mathrm{aC}+\mathrm{b})$ & $\mathrm{i}=14.1 \mathrm{C}-0.88$ \\
Correlation coefficient $(\mathrm{r})$ & 0.998 \\
Limit of detection $(\mu \mathrm{g} / \mathrm{mL})$ & 0.0993 \\
$\mathrm{RSD}(\mathrm{n}=9)$ & $3.6 \%(\mathrm{C}=0.8 \mu \mathrm{g} / \mathrm{mL})$ \\
\hline
\end{tabular}

Assay for venlafaxine capsules: Not less than 10 commercial capsules of venlafaxine(Kanghong $®$, amount declared $25 \mathrm{mg}$ venlafaxine per capsule) were used. The content of each capsule was independently dissolved in $10 \mathrm{~mL}$ water and diluted to a final volume of $50.0 \mathrm{~mL}$ with the same solvent. A $20 \mu \mathrm{L}$ aliquot of each solution was transferred to a electrolyte cell, bubbled with nitrogen during $6 \mathrm{~min}$ and recorded. The $\mathrm{mg}$ amount of venlafaxine in the sample solution was calculated from the prepared standard calibration curve.

In order to obtain the precision and accuracy of the developed method, a recovery study was performed. These results (Table-2) reveal that the method has an adequate precision and accuracy and consequently, can be applied to the determination of venlafaxine in commercial dosage (capsules). Also, we can conclude from these experiments that typical excipients included in the drug formulation (Starch sodium glycolate, sucrose, lactose spray dried, magnesium stearate, microcrystalline cellulose) do not interfere with the selectivity of the method and previous separation or extractions are not necessary.

The proposed DPSV method was applied successfully to capsule assay. With comparative purposes a HPLC analysis was also carried out (Table-2). The results obtained in the uniformity content test by each applied method were compared by applying F-test (variance proportion) and then the $t$-test
TABLE-2

INDIVIDUAL CAPSULE ASSAY OF VENLAFAXINE

\begin{tabular}{ccc|cc}
\hline \multirow{2}{*}{ Capsule } & \multicolumn{2}{c|}{ HPLC } & \multicolumn{2}{c}{ DPSV } \\
\cline { 2 - 5 } & Found (mg) & Found (\%) & Found (mg) & Found (\%) \\
\hline 1 & 23.78 & 95.1 & 24.35 & 97.4 \\
2 & 24.13 & 96.5 & 23.85 & 95.4 \\
3 & 24.55 & 98.2 & 24.34 & 97.4 \\
4 & 24.89 & 99.6 & 24.66 & 98.6 \\
5 & 23.80 & 95.2 & 24.43 & 97.7 \\
6 & 23.13 & 92.5 & 23.75 & 95.0 \\
7 & 24.95 & 99.8 & 25.52 & 102.1 \\
8 & 23.35 & 93.4 & 23.40 & 93.6 \\
9 & 24.40 & 97.6 & 24.70 & 98.8 \\
10 & 24.93 & 99.7 & 26.08 & 104.3 \\
Average & 24.20 & 96.8 & 24.51 & 98.0 \\
SD & 0.66 & 2.65 & 0.81 & 3.22 \\
CV $(\%)$ & 2.7 & 2.7 & 3.3 & 3.3 \\
\hline
\end{tabular}

${ }^{a}$ Declared amount/capsule: $25 \mathrm{mg}$ venlafaxine.

$(p<0.05, \mathrm{n}=10)$ and it was concluded that no significant differences exist between them and that they were statistically equivalent.

Finally, it is concluded that the DPSV method is enough for the venlafaxine determination in pharmaceutical forms, as it exhibits an adequate accuracy, reproducibility and selectivity.

\section{ACKNOWLEDGEMENTS}

The author gratefully acknowledged the financial support of this project by the National Science Foundation of China (No. 20865003), the Jiangxi Province Natural Science Foundation (2007JZH2644) and the Jiangxi Province Education Department Science Foundation (GJJ13110).

\section{REFERENCES}

1. J.S. Oliver, G.D. Burrows and T.R. Norwood, CNS Drugs, 15, 941 (2001).

2. E.A. Muth, J.A. Moyer, J.T. Haskins, T.H. Andree and G.E.M. Husbands, Drug Dev. Res., 23, 191 (1991).

3. S.N. Makhija and P.R. Vavia, J. Pharm. Biomed. Anal., 28, 1055 (2002).

4. M. Matoga, F. Pehourcq, K. Titier, F. Dumora and C. Jarry, J. Chromatogr. $B, 760,213$ (2001).

5. B.N. Patel, N. Sharma, M. Sanyal and P.S. Shrivastav, J. Pharm. Biomed. Anal., 47, 603 (2008).

6. R. Mandrioli, L. Mercolini, R. Cesta, S. Fanali, M. Amore and M.A. Raggi, J. Chromatogr. B, 856, 88 (2007).

7. W. Liu, F. Wang and H.-D. Li, J. Chromatogr. B, 850, 183 (2007).

8. W. Liu, H.-L. Cai and H.-D. Li, J. Chromatogr. B, 850, 405 (2007).

9. J.L.F.C Lima, D.V. Loo, C. Delerue-Matos and A.S.R. da Silva, IL Farmaco, 54, 145 (1999).

10. J. Wang, Analytical Electrochemistry, Wiley-VCH, New York, edn. 2 (2000).

11. E. Maggi, E. Pianezzola and G. Valzelli, Eur. J. Clin. Pharm., 21, 251 (1981).

12. D.R. Hicks, D. Wolaniuk, A. Russell, N. Cavanaugh and M. Kraml, Ther. Drug Monit., 16, 100 (1994).

13. P. Zuman, The Elucidation of Organic Electrode Process, Academic Press, New York (1969).

14. P. Delahay, New Instrumental Methods in Electrochemistry, Interscience, New York (1966).

15. E. Laviron, L. Roullier and C. Degrand, J. Electroanal. Chem. Interf. Electrochem., 112, 11 (1980).

16. J.N. Miller and J.C. Miller, Statistics and Chemometrics for Analytical Chemistry, Pearson Eduction Limited, London, edn. 4 (2000). 